
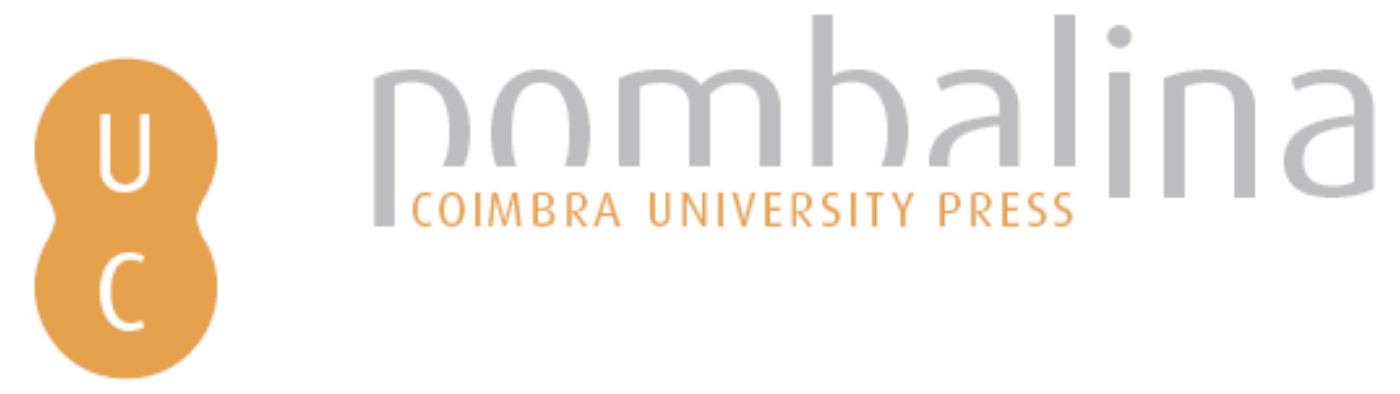

\title{
Determinação da taxa de humidade superficial de um solo granítico usando o valor da amplitude do sinal do GPR
}

\author{
Autor(es): $\quad$ Azevedo, J. P.; Oliveira, J. D.; Pereira, B. S.; Fernandes, F.; Mota, T. \\ Publicado por: Imprensa da Universidade de Coimbra \\ URL \\ persistente: URI:http://hdl.handle.net/10316.2/31455 \\ DOI: $\quad$ DOI:http://dx.doi.org/10.14195/978-989-26-0531-9_25 \\ Accessed : $\quad$ 26-Apr-2023 11:35:38
}

A navegação consulta e descarregamento dos títulos inseridos nas Bibliotecas Digitais UC Digitalis, UC Pombalina e UC Impactum, pressupõem a aceitação plena e sem reservas dos Termos e Condições de Uso destas Bibliotecas Digitais, disponíveis em https://digitalis.uc.pt/pt-pt/termos.

Conforme exposto nos referidos Termos e Condições de Uso, o descarregamento de títulos de acesso restrito requer uma licença válida de autorização devendo o utilizador aceder ao(s) documento(s) a partir de um endereço de IP da instituição detentora da supramencionada licença.

Ao utilizador é apenas permitido o descarregamento para uso pessoal, pelo que o emprego do(s) título(s) descarregado(s) para outro fim, designadamente comercial, carece de autorização do respetivo autor ou editor da obra.

Na medida em que todas as obras da UC Digitalis se encontram protegidas pelo Código do Direito de Autor e Direitos Conexos e demais legislação aplicável, toda a cópia, parcial ou total, deste documento, nos casos em que é legalmente admitida, deverá conter ou fazer-se acompanhar por este aviso.

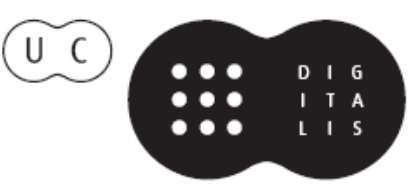





\title{
DETERMINAÇÁO DA TAXA DE HUMIDADE SUPERFICIAL DE UM SOLO GRANÍTICO USANDO O VALOR DA AMPLITUDE DO SINAL DO GPR
}

\section{SURFACE MOISTURE ESTIMATION OF A GRANITIC SOIL FROM AMPLITUDE ATTRIBUTE OF GPR}

\author{
J. P. Azevedo ${ }^{1}$, J. D. Oliveira ${ }^{1}$, B. S. Pereira ${ }^{1}$, F. Fernandes ${ }^{2} \&$ T. Mota ${ }^{3}$
}

\begin{abstract}
Resumo - Neste trabalho apresentam-se os resultados obtidos em experiências controladas numa parcela de terreno granítico, realizadas com o GPR (Ground Pentrating Radar) e com o intuito de verificar a capacidade desta técnica em detectar variaçóes superficiais de humidade. Este trabalho focou-se essencialmente na avaliação da capacidade do GPR em obter dados oriundos da reflexão da onda electromagnética na superfície do solo para determinar possíveis correlaçóes entre as variaçóes da amplitude do sinal e a taxa de humidade presente na camada mais superficial. Ao equipamento de GPR usado foi acoplado uma antena com uma frequência central de $800 \mathrm{MHz}$. Foram efetuados perfis de GPR em vários períodos climáticos distintos e, simultaneamente, foram realizadas mediçóes do teor de humidade usando o sensor de humidade TethaProbe ML2x, com o objetivo de comparar os valores de amplitude do sinal refletido pela superfície com os teores de humidade medidos com o sensor. Os resultados apontam para a existência de uma correlaçáo entre os valores da amplitude e a humidade no solo.
\end{abstract}

Palavras-chave - GPR, amplitude, teor de humidade, solo

Abstract - This paper presents the results obtained in controlled experiments conducted on a parcel of granitic soil with GPR (Ground Pentrating Radar) equipment in order to verify the capability of this technique to detect variations in surface moisture. This work focused

\footnotetext{
${ }^{1}$ Edifício IEMinho - Lugar de Casal 4730-575 Soutelo - Vila Verde; geral@sinergeo.pt

${ }^{2}$ Universidade Lusíada - Largo Tinoco de Sousa 4760-108 VNF; francisco.fernandes@fam.ulusiada.pt

${ }^{3}$ Departamento de Experimentação da EVAG - CVRVV Campos Lima 4970-249 Paçô AVV; tmota@ vinhoverde.pt
} 
primarily on assessing the ability to obtain data from the reflection of the electromagnetic wave on the soil surface to verify possible correlations between variations in the signal's amplitude and the moisture content in the outermost layer. The GPR equipment used was coupled with an antenna of $800 \mathrm{MHz}$ of central frequency. Profiles were made with the GPR equipment in different time periods and, simultaneously, the moisture content was measured using the humidity sensor TethaProbe ML2x, in order to compare the values of amplitude of the signal reflected by the surface with the values measured with the moisture sensor. The results indicate the existence of a correlation between the signal's amplitude and the moisture content within the soil.

Keywords - GPR, amplitude, surface moisture, soil

\section{1 - Introduçáo}

A capacidade de obter valores de taxas de humidade sobre grandes áreas é fundamental em diversas aplicaçóes agrícolas, hidrogeológicas e ambientais. Por outro lado e tomando a cultura da vinha como uma aplicação agrícola importante, a gestáo racional da rega em terrenos vitícolas e o conhecimento do volume de água no solo (VAS) disponível durante todo o processo de crescimento da videira e maturação da uva é fundamental para a qualidade do fruto produzido.

Nesse sentido, o projeto AGROCONTROL, cofinanciado pelo "ON.2 O Novo Norte" e QREN através do Fundo Europeu de Desenvolvimento Regional (FEDER), tem por objetivo estudar metodologias alternativas, para a determinaçáo do conteúdo de água no solo, nomeadamente, o rastreio de vastas áreas de cultivo de vinha utilizando o radar de penetraçáo geotécnica (ou ground penetrating radar, vulgo GPR).

Para calcular o teor de humidade presente no solo são comummente utilizados métodos baseados na leitura da resistividade eléctrica em sensores enterrados em diferentes pontos e a diferentes profundidades; métodos gravimétricos, entre outros, ou métodos indiretos através do estado hídrico da planta (potencial hídrico foliar ou do ramo; temperatura das folhas ou do coberto; variação do diâmetro do tronco, fluxo de seiva). Apesar da elevada precisão desses métodos, acabam por ser muito morosos, e devido ao seu carácter pontual, são geralmente limitados a pequenas áreas e avaliados por amostragem. Realça-se também que estes métodos são invasivos, pontuais e, por isso, só aplicáveis com limite espacial. Ora, para monitorizar grandes áreas ocupadas por vinhas (e outras culturas), são necessárias técnicas e métodos que permitam mapear rapidamente essas áreas, com precisão compatível com o tipo de dados necessários e de maneira totalmente náo destrutiva, possibilitando a repetibilidade destes ensaios sem perda de precisão.

O GPR é uma técnica geofísica que usa energia electromagnética (ondas rádio) para mapear o subsolo. A energia electromagnética emitida é transmitida para o solo, sendo modificada, e parcialmente reflectida, pelos contrastes na interface entre os diferentes materiais presentes no subsolo. Estes contrastes dependem das propriedades desses materiais, nomeadamente, a permissividade eléctrica $(\varepsilon)$, ou constante dielétrica $\left(\varepsilon_{\mathrm{r}}\right)$, e permeabilidade magnética $(\mu)$, cujos valores modificam a amplitude e a velocidade de propagação 
das ondas emitidas. O VAS está relacionado com esses parâmetros, que são obtidos através de diferentes metodologias de ensaios.

$\mathrm{Na}$ banda de frequências usadas pelo GPR, a velocidade de propagação da onda electromagnética $(\mathrm{EM})$ é principalmente determinada/afectada pela constante dielétrica, $\varepsilon_{\mathrm{r}}$, a qual possui valores próximos de 80 para a água, entre 3 e 10 para os principais minerais constituintes do solo, e 1 para o ar (ANNAN, 1998 in PAIXÃO, 2006).

\section{2 - Materiais e métodos}

A determinação da variação do VAS através do GPR pode ser realizada recorrendo a diferentes métodos, sendo cada um caracterizado por diferentes equipamentos, processos e dados obtidos (CHARLTON, 2000; HUISSMAN et al., 2003; LUNt et al., 2005). No âmbito deste projeto, o objetivo é obter informação qualitativa sobre o teor de humidade de modo fiável e expedito, dada a elevada área da parcela. Nesse sentido, a técnica selecionada para ser estudada foi a da "reflexão à superfície", que se baseia na obtenção de perfis onde é registada a amplitude de reflexão do sinal na camada mais superficial do solo. Este método consiste em colocar uma antena a uma altura suficientemente elevada de modo que o sinal de onda direta seja distinto do sinal da reflexão da superfície do solo (DANIELS, 2004). A Fig. 1 ilustra o protótipo destinado a manter a antena a uma determinada distância acima do solo e a permitir percorrer rapidamente longas extensóes bem como a localização geográfica da parcela.
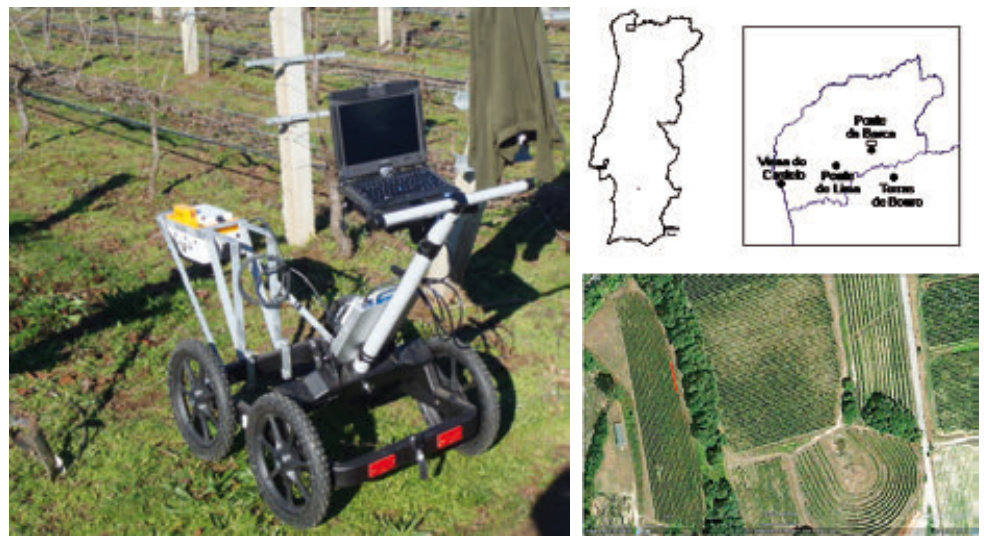

Fig. 1 - Protótipo usado no trabalho de campo com a antena acoplada a $40 \mathrm{~cm}$ do solo e localização geográfica da parcela.

Os radar-gramas obtidos correspondem à "força da reflexáo" do solo que depende do contraste entre as constantes dielétricas dos materiais geológicos investigados, bem como do ar e água. Enquanto a $\varepsilon_{\mathrm{r}}$ do ar é 1, a do solo varia em função da sua mineralogia e em função do teor em água. Tendo em conta que a $\varepsilon_{\mathrm{r}}$ da água é de 81 , torna-se evidente que um solo seco terá uma constante dielé- 
trica muito menor que um solo saturado. Consequentemente, um solo molhado irá refletir mais energia que um solo seco resultando, respectivamente, numa amplitude maior e menor.

Os resultados preliminares apresentados neste trabalho foram obtidos numa parcela de vinha - vinhão, na Quinta Campos Lima, localizada no concelho dos Arcos de Valdevez. Do ponto de vista litológico, o terreno corresponde a um solo residual granítico, com densidade média de $1.14 \mathrm{~g} / \mathrm{cm}^{3}$ e porosidade média $0.56 \mathrm{~m}^{3} /$ $\mathrm{m}^{3}$, típica de solos ricos em matéria orgânica. Apresenta um elevado grau de meteorização (alteração física e química) com espessura variável. A parcela apresenta uma topografia ligeiramente inclinada para Sul, correspondendo o ponto mais elevado a uma altitude de $81 \mathrm{~m}$ e o ponto mais baixo a uma altitude de $69 \mathrm{~m}$. As videiras estão plantadas com um espaçamento médio de $2 \mathrm{~m}$ e estão conduzidas em bardos com $3 \mathrm{~m}$ de separação.

As mediçôes foram realizadas numa extensão de 24 metros, no centro da parcela entre 2 bardos evitando graus de compactação elevados devido à passagem dos veículos agrícolas. Foi utilizada uma antena de $800 \mathrm{MHz}$, operada a uma distância acima do solo de $40 \mathrm{~cm}$, cujo espaçamento entre o transmissor e o receptor é fixo $(14 \mathrm{~cm})$. O intervalo entre os pontos de aquisição é de $0,2 \mathrm{~m}$, o que representa cerca de cinco traços de radar-grama por metro e uma janela temporal de $10 \mathrm{~ns}$ (tempo de leitura).

Foram realizadas quatro campanhas de campo para obter informaçóes sobre as condiçôes de humidade do solo, em períodos climáticos distintos. As primeiras 3 campanhas decorreram no dia 8, 16 e 23 de setembro de 2011, e procurou-se detectar variaçóes temporais e espaciais de humidade sobre condiçóes naturais de solo, particularmente durante o período estival. A última campanha de campo realizou-se no dia 28 de outubro correspondendo a um período climático mais húmido e após os primeiros dias de precipitação do outono. Foram medidos os valores do teor de humidade do solo, com o sensor ThetaProbe (Soil Moisture sensor Type ML2x) ao longo do mesmo perfil para comparaçáo com os valores da amplitude do sinal da onda refletida pela superfície do solo.

Os radar-gramas adquiridos foram posteriormente processados com software especializado. Este processamento teve como finalidade a aquisiçáo dos valores das amplitudes do sinal para comparação com os valores obtidos com o sensor de humidade.

\section{3 - Resultados e discussão}

Para obter valores de teor de humidade natural do solo, para comparação com os dados de GPR, foram efetuadas mediçóes com recurso ao sensor TethaProbe ao longo da mesma perfilagem e com um espaçamento constante de 2 metros (Tabela 1). 
Tabela 1 - Valores de humidade no solo em percentagem obtidos com o ThetaProbe.

\begin{tabular}{ccccc}
\hline & Data & & & \\
\hline \\
\hline
\end{tabular}

Relativamente aos resultados de amplitude do sinal registados com o GPR, surgiram inicialmente vários problemas, tais como: a) o impacto da rugosidade do terreno, (b) a definição da altura da antena acima da superfície do solo, (c) o efeito causado pelo coberto vegetal e (d) a definição da configuração dos parâmetros do sinal da antena. Mediçóes iniciais demonstraram que o coberto vegetal tinha um efeito negligenciável nos dados, enquanto a rugosidade do terreno tinha um impacto menor sobre a "quantidade" de reflexões recebidas durante as mediçôes.

Depois de efetuada a calibração do equipamento, foi possível iniciar a aquisição de radar-gramas de forma sistemática, bem como a medição dos teores de humidade natural com o sensor TethaProbe. A Fig. 2, ilustra um exemplo do tipo de dados de reflexão da superfície adquiridos com a antena de $800 \mathrm{MHz}$ instalada no protótipo ilustrado na Fig. 1. 


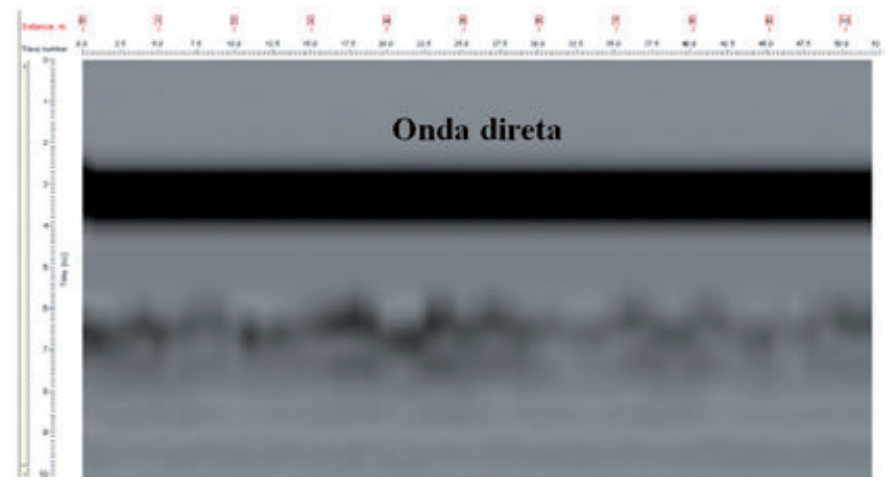

a)

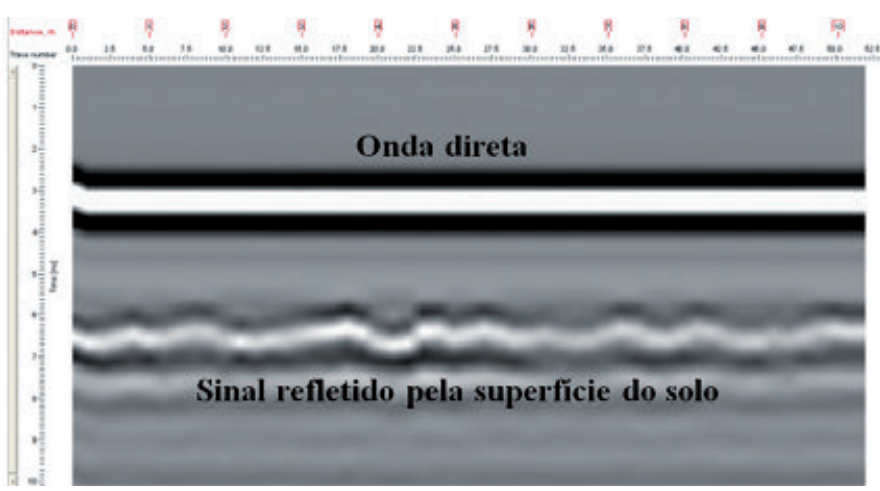

b)

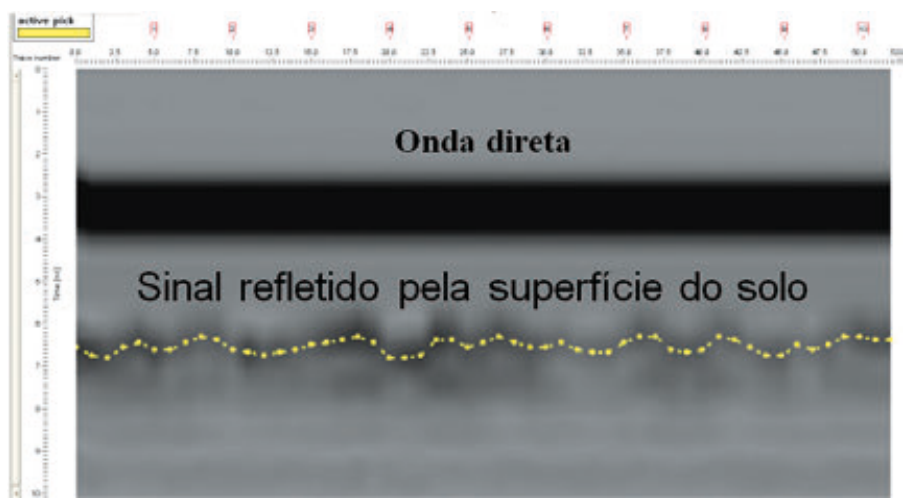

c)

Fig. 2 - Exemplos de radar-gramas registados com a antena de $800 \mathrm{MHz}$ - a); após processamento através da filtragem de baixas frequências e determinação da "força de reflexão" - b); a linha amarela indica os picos de amplitude máxima do sinal - c). 
$\mathrm{O}$ afastamento da antena relativamente ao solo permite diferenciar claramente o sinal da onda direta da onda refletida (Fig. 2.a). Os dados do GPR foram processados utilizando dois filtros: DC removal, e reflection strength que traça, com precisão, as variaçóes de amplitude ao longo das fronteiras de reflexão. A partir dos radar-gramas, e recorrendo a uma folha de cálculo, foi possível discriminar os valores de amplitude da onda refletida pela superfície do solo.

Os resultados da amplitude da onda reflectida obtidos com a antena de $800 \mathrm{MHz}$ demonstraram ser coerentes com os resultados medidos com o sensor de humidade apresentados na Tabela 1, ou seja, observa-se que em condiçóes de solo mais húmido o valor da amplitude é maior do que em condiçôes de solo mais seco (Fig 3). Verifica-se claramente uma diminuição do valor da amplitude do sinal sempre que há uma diminuição do teor de humidade medido com o sensor, sobretudo ao longo das três primeiras campanhas. Da mesma forma se verifica um incremento da amplitude do sinal obtido na última campanha em outubro. Nesse sentido, parece existir claramente uma relação entre o coeficiente de reflexão associado à interface ar-solo e humidade do solo. A relação aponta igualmente, que os coeficientes de reflexão expressos pela amplitude do sinal, são mais sensíveis às variaçóes de humidade em intervalos menores (Fig. 4).

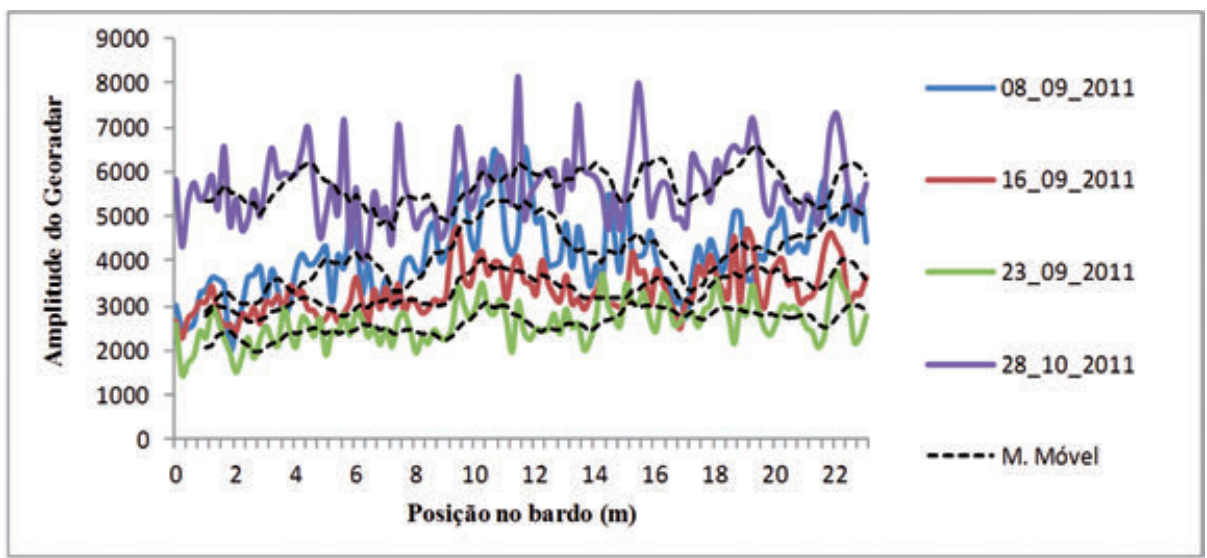

Fig. 3 - Variação espacial da amplitude do sinal da onda directa ao solo nas quatro campanhas efectuadas.

Adicionalmente, traçando o gráfico que relaciona todos os valores da taxa de humidade no solo obtidos com o sensor de humidade com o valor da amplitude do sinal registado por GPR, verifica-se que existe uma relaçáo exponencial entre eles, o que sugere, como referido anteriormente, uma maior sensibilidade do equipamento GPR em relação a pequenas variaçóes do conteúdo em humidade (Fig. 5). Esta conclusão é relevante pois estas pequenas variações de humidade são importantes para a evolução do fruto/da vinha, para além do facto que é precisamente na época estival que estas pequenas variaçóes são importantes de identificar. Torna-se portante promissora a aplicação desta metodologia (mediçóes da humidade do solo a partir de reflexóes da superfície).

Nesse sentido, parece possível atribuir a determinados valores de amplitude de sinal uma determinada percentagem de humidade. No entanto, verifica-se alguma dispersão nos dados, facto que resulta diretamente da sua escassez e do método de correlação ainda precisar de ser ajustado. 


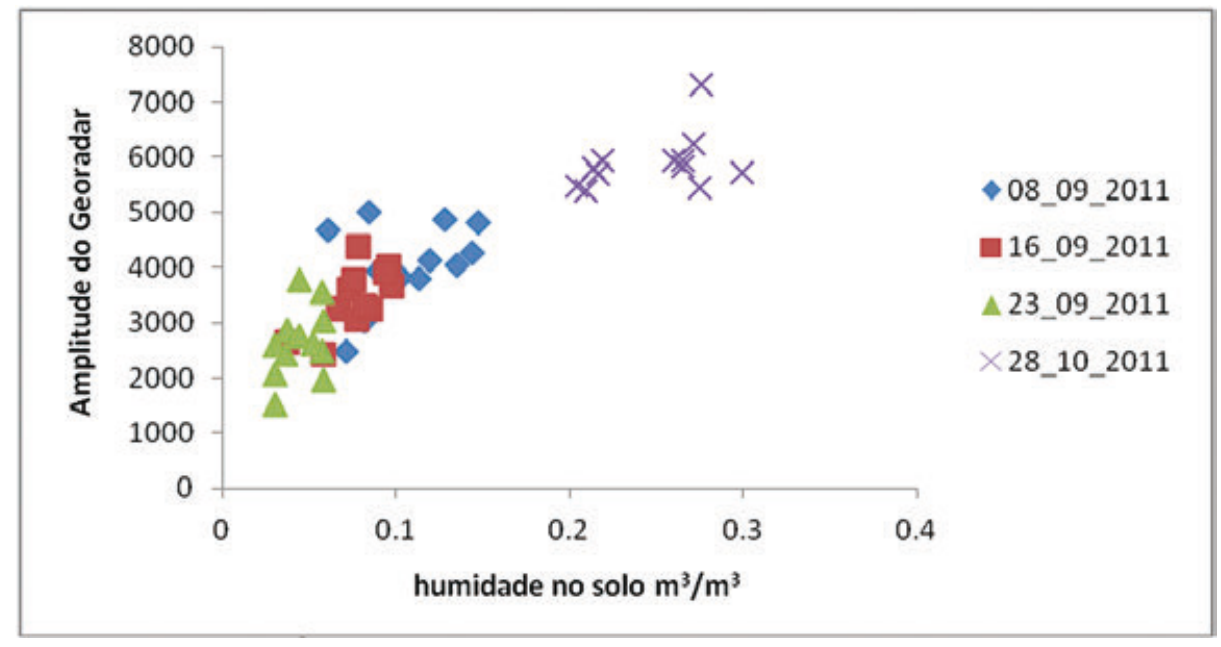

Fig. 4 - Relação entre a amplitude do Georadar e a humidade no solo.

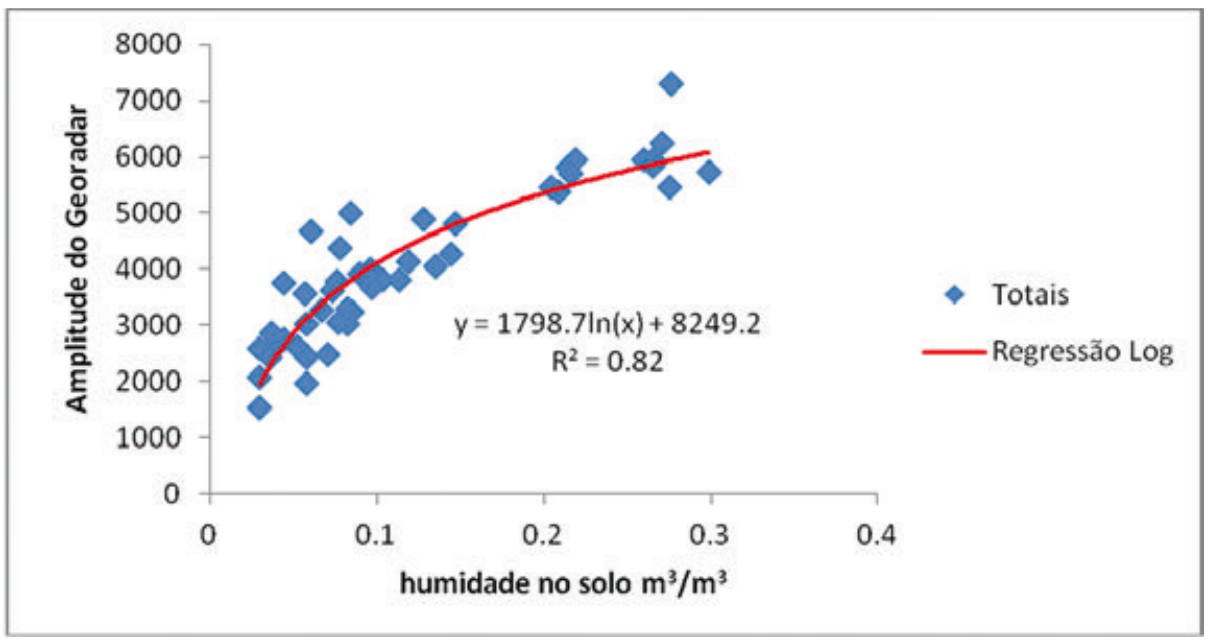

Fig. 5 - Relação exponencial entre a amplitude do Georadar e a humidade no solo.

\section{4 - Conclusões}

Este estudo centrou-se na avaliação da utilidade e precisão do equipamento GPR na avaliação de variaçóes superficiais de humidade a partir dos dados de amplitude das ondas reflectidas. Apesar de promissora, esta metodologia ainda não proporciona a precisão e robustez dos métodos tradicionais, que são muito morosos e posicionais em trabalho de campo. Os resultados mostram que foram obtidas importantes relaçóes entre os valores registados pelo GPR através do método por reflexão à superfície e os valores obtidos pelo sensor de humidade TethaProbe. Verificou-se ainda existir uma diferença da 
amplitude do sinal refletido, pela superfície do solo seco e solo molhado, mais acentuada quando o valor de humidade é baixo. Para estabelecer valores estatísticos mais fiáveis será necessário a realização de mais ensaios para obtenção de mais dados.

No entanto, ainda estão por aferir completamente alguns parâmetros, nomeadamente, qual a melhor altura para a realização deste ensaio tendo em conta o tipo de solo e a rapidez com que a água se evapora ou é absorvida, assim como a eficácia do equipamento em manter a reprodutibilidade de resultados em diferentes épocas do ano e para o mesmo tipo de solo. Mais estudos de campo serão necessários para determinar relaçóes, sobretudo petrofísicas relacionadas com condiçóes heterogéneas de campo, que atualmente limitam a adopção do GPR como ferramenta para determinação da taxa de humidade do solo.

\section{Referências Bibliográficas}

CHARLTON M. (2000) - Small Scale Soil-Moisture Variability Estimated Using Ground Penetrating Radar. Proceedings of the Eighth International Conference on Ground Penetrating Radar, SPIE Vol. 4084, p. 798-804.

DANIELS, D.J. (2004) - “Ground Penetrating Radar - 2nd Edition.” Radar, sonar, navigation and avionics series 15, IEE, London, UK, ISBN 0-86341-360-9, p. 726.

HUISSMAN J., HUBBARD S., REDMAN J. \& ANNAN A. (2003) - Measuring soil water content with ground penetrating radar: A review. Vadose Zone Journal Vol. 2, p. 476-491.

LUNT I., HUBBARD S. \& RUBIN Y. (2005) - Soil moisture content estimation using ground penetrating radar reflection data. Journal of Hydrology 307, p. 254-269.

PAIXÃO M., PRADO M. \& DIOGO L., (2006) - Análise do emprego do GPR para estimar o teor de humidade do solo a partir de um estudo na cidade de Sáo Paulo. Revista Brasileira de Geofísica, p. 189-198. 